\title{
O trabalho infanto-juvenil na sociedade capitalista
}

\author{
Francisco Carlos Lopes da Silva
}

\begin{abstract}
RESUMO
Este artigo discute a questão do trabalho infanto-juvenil e as suas diversas manifestações articulado às relações capitalistas de produção; analisa os dados do IBGE-90, PNAD-90/97, OIT, UNICEF-97; analisa as causas de sua utilização e intensificação durante a revolução industrial e a continuidade do fenômeno na sociedade contemporânea; considera-o como importante no rebaixamento do custo de mão-de-obra e nas vantagens que traz no mercado globalizado; analisa a sua inserção na cadeia produtiva e as formas de exploração, precarização e flexibilização dos direitos; avalia as repercussões que o trabalho infanto-juvenil apresenta para a saúde e desenvolvimento e conclui que a superação da exploração do trabalho infanto-juvenil passa por um novo modelo político-econômico, com base na justiça social.
\end{abstract}

Palavras-chave: capitalismo, trabalho infanto-juvenil, saúde da criança e adolescente trabalhadora.

\begin{abstract}
The issue of infant-juveline work is discussed and so are the several ways linked to capitalistic production relations. IBGE-90/97, OIT, UNICEF-97 data are analysed. The causes for the use of this kind of work and its intensification and continuity during the industrial revolution are analysed. Low costly labor-work and its advantages in a globalized market are found important. This kind of work in a productive chain and its explorations and poor flexibilization of rights is analysed. It is concluded that the over-use of infant-juveline work has been through a new political-economic model based upon social justice.

Key-words: infant-juveline work, working children and teenagers 's health.
\end{abstract}

Você já trabalhou?

"Em Minas também, aqui trabalhava, cuidava de cavalo a noite inteira, passava fome, sede, ficava dois ou três dias sem tomar banho com a mesma roupa".

Voce recebia algum pagamento por este trabalho?

"Pagamento que eu recebia era lugar de dormir e morar só, comida e roupa e olhe lá ainda. Além de cortar capim na chuva, cuidar de cavalo, catar papelão, comecei a fazer isso dos nove até os onze".

Como fazia este trabalho?

"Sozinho. Picando eu colocava o capim no toco e ficava picando capim, aquele capim assim grande, ficava picando até a noite inteira, ia até uma hora, duas horas da manhã, picava a carroça toda e colocava pros cavalos, aí na hora que ia dormir já tinha que levantar cedo, 4 ou 5 horas da manhã, já para soltar os cavalos pros pastos, cortar mais capim, rapar curral tudo, aí algumas vezes eu se cortava porque era noite assim, não dava para enxergar direito. (EA)

\section{Introdução}

As contradições do sistema capitalista geram um processo de desigualdade social e econômica que, no caso brasileiro, se caracteriza por uma divisão estrutural e desumana. O trabalho infanto-juvenil, em muitos casos na forma de semi-escravidão, contribui para o funcionamento desse sistema como um fator necessário para a sua manutenção e reprodução. Segundo PEREIRA (1994), milhões de pequenos brasileiros neste país estão no campo, nas plantações de café, amendoim, chá, no corte do babaçu, no sisal, nas inúmeras oficinas 
de quintal. São patrulheiros mirins nas cidades, aprendizes de fábricas, guardadores de carro, vendedores de rua, jornaleiros, carregadores de cargas, empacotadores, engraxates, pequenas lavadeiras, office-boys, recolhedores de lixo, reciclagem de lixões, furtadores de toca-fitas, relógios, carteiras, explorados sexualmente e auxiliares no mundo do tráfico de drogas.

MIRANDA (1998) considera que o tipo de atividade que essas crianças trabalhadoras desenvolvem, pela sua insalubridade, não só não educa a criança pauperizada na direção do seu crescimento e realização como ser social, mas ainda a coloca em risco de vida e não gera renda prometida, apenas permitindo a sua sobrevida dentro da miséria e opressão.

Observa-se que formas antigas de exploração da humanidade, como a escravidão, permanecem no mundo contemporâneo das moderníssimas tecnologias. A criança ou o adolescente, submetidos a essa situação, confirmam a estreita conexão entre pobreza, exploração precoce no trabalho e evasão escolar. Esta tríade é uma presença constante na história de vida de milhões de brasileiros e é fartamente confirmada por diversos estudos e pesquisas. Segundo GRACIANI (1997), as atividades exercidas por estes pequenos trabalhadores assumem uma função fundamental no sistema econômico: "O trabalho infanto-juvenil é um marco conseqüente e necessário na lógica do sistema e ocupa, ao mesmo tempo, função importante no processo de acumulação de lucros, que destrói precoce e radicalmente os potenciais de trabalho" (GRACIANI, 1997, p. 94).

O UNICEF (1997) estabelece que o trabalho infantil adquire características de exploração quando envolve: atividade em período integral, quando a criança ainda é muito jovem; muitas horas de atividade; atividade que provoque excessivo estresse físico, emocional ou psicológico; atividade e vida nas ruas em más condições; remuneração inadequada; responsabilidade excessiva; atividade que impeça o acesso à educação; atividade que comprometa a dignidade e a auto-estima da criança, como escravidão ou trabalho servil e exploração sexual; atividade prejudicial ao pleno desenvolvimento psicológico.

O trabalho infanto-juvenil sempre esteve presente na história da humanidade, assumindo a forma de mercadoria na sociedade capitalista. O "pensamento econômico burguês" justifica a exploração do trabalho, aliás engendra teorias que o justificam. Ideologicamente, no sentido de falsificação da realidade, ele é identificado como um fenômeno social complexo, explicado numa mesma ordem de igualdade por fatores econômicos, sociais e culturais.

$\mathrm{Na}$ perspectiva do pensamento crítico, contrapondo-se às explicações que colocam fatores políticos, sociais e econômicos num mesmo patamar de igualdade, mas ao mesmo tempo reconhecendo a complexa interação existente entre eles, aponta-se a influência preponderante das relações econômicas para a explicação deste fenômeno, ou seja, a forma como o homem organiza o comércio, a produção e o consumo determina a sua organização social (MARX, 1980).

Não obstante, o progresso econômico, científico e tecnológico experimentado pela sociedade capitalista durante a revolução industrial, as transformações no modo de produção favorecem a exploração do trabalho humano e, por conseqüência, o trabalho de crianças e adolescentes se intensifica. "De um lado nós temos um progresso histórico e fator de desenvolvimento econômico da sociedade e, do outro, meio civilizado e refinado de exploração" (MARX, 1980, p. 418).

A introdução de máquinas no processo produtivo possibilita ao capital, entre outras coisas, a utilização intensa do trabalho de crianças e adolescentes de uma maneira diferente do que ocorria nas sociedades anteriores. As máquinas passaram a ser alimentadas também por crianças e adolescentes: o trabalho humano se dividiu e foi reduzido à tarefa de alimentar autômatos.

Dessa forma, as relações capitalistas industriais mudam a forma de aprendizado e inserção no mundo do trabalho dos homens. O aprendizado não ocorre mais nas casas, nas corporações de ofícios, onde se trocava o trabalho pelo conhecimento de um ofício, mas agora diretamente inserido no mundo da produção em atividades simples e automatizadas. A divisão do trabalho extingue os ofícios, descarta o saber especializado do trabalhador sobre o processo de trabalho e possibilita que crianças e adolescentes rapidamente sejam introduzidas nas fábricas e manufaturas. Isso ocorre dada a simplificação de tarefas e a troco de um salário para contribuir com a subsistência da família, posto que o valor da força de trabalho do adulto também se encontra desvalorizado em função da divisão e precarização do trabalho. 


\title{
Segundo Marx:
}

\begin{abstract}
Tornando supérflua a força muscular, a maquinaria permite o emprego de trabalhadores sem força muscular ou com desenvolvimento físico incompleto, mas com membros flexíveis. Por isso, a primeira preocupação do capitalista ao empregar a maquinaria foi a de utilizar o trabalho de mulheres e das crianças. Assim, de poderoso meio de substituir o trabalho e trabalhadores, a maquinaria transformou-se imediatamente em meio de aumentar o número de assalariados, colocando todos os membros da família do trabalhador, sem distinção de sexo e de idade, sob o domínio direto do capital. O trabalho obrigatório para o capital tomou o lugar dos folguedos infantis e do trabalho livre realizado em casa, para a própria família, dentro dos limites estabelecidos pelos costumes. (MARX, 1980, p. 450-451).
\end{abstract}

Portanto, a utilização do trabalho infanto-juvenil no processo produtivo tem a sua razão de ser nas relações sociais capitalistas e na relação que se estabelece com o novo modo de produzir. Ela não é resultado da vontade das famílias dos trabalhadores, muito menos de determinada tradição cultural, como os ideólogos do sistema capitalista costumam afirmar.

Essa transformação do processo produtivo implica também mudanças na forma de contratação da força de trabalho e na aceitação social do trabalho de crianças e adolescentes, ou seja, ocorre um processo de precarização do trabalho em geral, bem como uma mudança de concepção de homem, sociedade e educação. Conforme MARX (1980):

"[...] Ela revoluciona radicalmente o contrato entre o trabalhador e o capitalista, contrato que estabelece formalmente suas relações mútuas. Tomando por base a troca de mercadorias, pressupuséramos, de inicio, que o capitalista e o trabalhador se confrontam como pessoas livres, como possuidores independentes de mercadorias, sendo um o detentor do dinheiro e dos meios de produção e o outro o detentor da força de trabalho, mas agora o capital compra incapazes ou parcialmente capazes, do ponto de vista jurídico. Antes vendia o trabalhador sua própria força de trabalho, da qual dispunha formalmente como pessoa livre. Agora vende mulher e filhos. Torna-se traficante de escravos."(MARX, 1980, p.451)

As transformações no modo de produção ampliam a exploração do trabalho: vê-se que o capitalismo engendra o 'trabalho livre' e faz da criança, formalmente incapaz de participar do mercado de trabalho, um dos seus agentes. Sem liberdade jurídica plena, submetido à tutela dos pais, às determinações estruturais da sociedade e de sua família, surge a figura ambígua do menor trabalhador, essa figura de aparência de criança e atividade de homem, produzida pelo capitalismo, nas classes subalternas. (Oliveira, 1989, p. 224).

$\mathrm{O}$ final do século XX caracteriza-se por significativo desenvolvimento das bases materiais de produção; as atuais transformações decorrem da intensificação do uso de ciência e tecnologia ao processo produtivo. Estas mudanças traduzem-se na automação, nos componentes microeletrônicos adaptados à maquinaria e nas novas formas de organização dos trabalhadores no processo de produção. Este processo, também categorizado de reestruturação produtiva, tem como conseqüência fundamental para a classe trabalhadora a substituição do trabalho humano vivo pelo trabalho morto das máquinas, propiciando, dessa forma, o aparecimento do desemprego estrutural em todo o mundo.

Com o desemprego, reduzem-se as condições materiais de existência dos trabalhadores. Portanto, aumentam as desigualdades sociais e a pobreza, impossibilitando a manutenção da própria existência e de sua família.

\section{Segundo Kuenzer:}

Isto acontece em função da situação concreta do sistema produtivo, determinado por opções econômicas comprometidas com a inovação tecnológica, com a produção em grande escala e com a competitividade dos produtos no mercado externo. Em decorrência, o setor primário se moderniza, com o que passa a desmobilizar mão-de-obra, acentuando a migração que já era significativa desde os anos 40 , acarretando a formação de bolsões de pobreza nas periferias dos grandes centros urbanos, para onde se deslocam trabalhadores rurais em busca de ocupação. Com precária ou inexistente qualificação, esses trabalhadores 
são incorporados basicamente pelo mercado informal. [...] O setor secundário também se moderniza com a incorporação dos novos avanços tecnológicos, necessitando cada vez menos de mão-de-obra, dessa forma contribuindo com o aumento do desemprego; por último, [...] o setor terciário, por sua vez, embora sempre tenha se caracterizado como absorvedor residual de mão-de-obra não consegue incorporar a oferta da força de trabalho excedente muito superior à demanda. (KUENZER, 1988, p. 17-18).

Destaca-se que o processo migratório, que se inicia nos anos 40, do campo para a cidade, é resultado da força do latifúndio, da ausência de uma reforma agrária e de políticas que assegurem ao pequeno agricultor a permanência na terra. Junto a este fator, o processo de industrialização, com base em inovações tecnológicas que dispensam mão-de-obra, contribui para o aumento da miséria.

Hoje, vive-se uma situação paradoxal na economia capitalista: há um aumento da produtividade como nunca antes visto na humanidade, mas igualmente uma redução brutal dos postos de trabalho. Entretanto, o trabalho de crianças e adolescentes continua sendo amplamente utilizado pelo capital, principalmente nos países em desenvolvimento; com raríssimas exceções encontramos na cadeia produtiva um produto que não tenha essa mão-de-obra.

Destaca-se que, no atual contexto econômico, de um mercado cada vez mais globalizado, com ênfase nas exportações, o baixo custo da mão-de-obra constitui uma vantagem comparativa muito significativa. "Entre os diversos fatores que contribuem para o rebaixamento dos custos do trabalho nos países em desenvolvimento está o trabalho infantil. Um posto de trabalho ocupado por uma criança substitui o de um adulto cuja remuneração seria certamente superior à da criança" (VEIGA, 1998, p. 31).

A questão é esta: a retribuição da força de trabalho de uma criança é inferior à de um adulto, o seu custo é menor e, na maioria das vezes, trabalha tanto quanto um adulto. Para o capitalista esta prática traz vantagem, pois, com o custo da força de trabalho reduzido, ele ganha competitividade, podendo reduzir os preços dos seus produtos no mercado.

Neste sentido pode-se dizer que as razões atuais da utilização da mão-de-obra de crianças e adolescentes continuam sendo as mesmas da revolução industrial, pois vive-se ainda numa sociedade capitalista, onde a acumulação do capital é a força propulsora que impulsiona o seu desenvolvimento.

A exploração do trabalho infanto-juvenil é mais presente no setor informal, onde se encontram empresas não registradas, subcapitalizadas, terceirizadas e dependentes de mercados instáveis ou sazonais, existentes em grande número nas zonas urbanas e rurais dos países em desenvolvimento. Esta mão-de-obra pode ser mais facilmente admitida do que a dos trabalhadores adultos, pode ser remunerada com menos de um salário mínimo, sem pagar os direitos trabalhistas, não tem representação sindical e, ainda, a clandestinidade protege aqueles que a empregam. Ele está presente mais nos países do capitalismo periférico, mas também nos países ricos entre as classes pobres.

A Organização Internacional do Trabalho - OIT, estima que existam no mundo cerca de 250 milhões de crianças trabalhadoras, em idade entre 5 e 14 anos, das quais cerca de 120 milhões trabalham em período integral (jornada cheia de trabalho, o que significa ao menos oito horas diárias de trabalho). Do total, 80 milhões trabalham em atividades de grande risco. Segundo VEIGA (1998), os dados do Fundo das Nações Unidas para a Infância e a Adolescência - UNICEF - confirmam os dados da OIT e indicam que milhões estão fora da escola, demonstrando aí uma relação entre trabalho infantil e abandono escolar.

As estatísticas no Brasil, segundo os dados do Instituto Brasileiro de Geografia e Estatística - IBGE, 1990 -, indicam que 7,5 milhões de crianças e adolescentes de 10 a 17 anos estão trabalhando, sendo que representam cerca de $11,6 \%$ da população economicamente ativa. Desse contigente, quase $40 \%$ tem entre 10 e 14 anos. Na zona rural representam $42,6 \%$ da força de trabalho. Dados mais atualizados do IBGE e do Centro de Estudos Avançados em Economia Aplicada da USP apresentam a seguinte distribuição regional do trabalho infantil na faixa etária de 10 a 14 anos: Nordeste 16\%, Sul 14,6\%, Centro-Oeste 10,7\%, Norte 9\%, Sudeste $6,5 \%$.

Fazendo um recorte mais específico para o Sul do país, o fenômeno do trabalho de crianças e adolescentes apresenta taxas elevadas; contudo, o fato de boa parte das crianças e adolescentes trabalharem não interfere na sua escolarização RIZZINI (1996).

Especificamente no Paraná, as informações contidas no "Mapa da Fome" (Mapa do Mercado de Trabalho no Brasil n. 1" - PNAD/90) indicam que a exploração da força de trabalho infanto-juvenil atinge padrões próximos ao de Estados mais pobres: 20,1\% das crianças entre 10 e 14 anos trabalham, número acima da média nacional. 
Dados mais recentes da Pesquisa Nacional de Amostra a Domicílio -PNAD, 1997 - mostram que a população economicamente ativa no Estado do Paraná, na faixa etária de 10 a 17 anos, é de 440.935, e em Curitiba e Região Metropolitana, na mesma faixa etária, é 67.096.

A semelhança entre a Revolução Industrial e o atual momento histórico é a intensificação da utilização da força de trabalho de mulheres e crianças. Diversas pesquisas demonstram o crescimento do trabalho desses grupos na economia. Não mais na indústria, mas principalmente no setor de serviços e ocupações desqualificadas.

Dados obtidos no II Tribunal Internacional Contra a Erradicação do Trabalho Infantil em maio de 1999, realizado na cidade de São Paulo, indicam um crescimento do trabalho infantil. A partir de dados da OIT e Departamento de Estado Americano, estima-se atualmente 300 milhões de crianças e adolescentes trabalhando. O primeiro Tribunal realizado em 1995 indicava 250 milhões; portanto, de 95 a 99, contata-se o crescimento 50 milhões aproximadamente.

A realidade do trabalho infanto-juvenil encontra-se no mundo todo, articulando-se às formas de superexploração e flexibilização dos direitos sociais e trabalhistas que marcam a globalização, onde a competitividade impõe rebaixamento dos custos de produção e reformas na legislação trabalhista e nos sistemas de seguridade social, adotados pelos países no sentido de adequar o tamanho do Estado à lógica da integração dos mercados.

Segundo diversas fontes, no mundo todo crianças e adolescentes são explorados, segundo a seguinte classificação: a) situação alarmante: trabalho penoso admitido, escravidão, prostituição, alistamento forçado; b) situação grave: trabalho penoso, prostituição freqüente e escravidão; c) situação média: trabalho penoso localizado e prostituição; d) situação geralmente boa: escolaridade respeitada e abusos severamente punidos. Com exceção dos seguintes países: Canadá, Noruega, Finlândia, Suécia, Dinamarca, Islândia, França, Suíça, e Austrália, todos os outros países do mundo apresentam algum tipo de exploração de crianças.

São inúmeros os exemplos em diferentes países, mostrando que a lógica da exploração do trabalho infanto-juvenil articula-se com a lógica da divisão internacional do capitalismo mundial, que se materializa na desigualdade entre norte e sul. "A guerra do Líbano, a agricultura arcaica na Guatemala, a industrialização selvagem no Brasil e na Tailândia, são causas diferentes que têm como conseqüências os mesmos efeitos, isto é, milhões de crianças aprendem a suar antes de rir" (TONIN, 1996, p. 12).

No Brasil a pesquisa feita por CERVINI e BURGER (1991), define o esquema conceitual para entender os fatores que levam à incorporação do trabalho infanto-juvenil ao mercado de trabalho. Segundo os autores, ela se deve a duas ordens de macrofatores: "primeiro à pobreza, que obriga as famílias a adotar formas de comportamento que incluem mão-de-obra dos filhos menores de idade; em segundo, a estrutura do mercado de trabalho, que oferece espaços apropriados à incorporação deste contingente" (CERVINI; BURGER, 1991, p. 19). Destacam-se ainda os valores simbólicos das famílias que preferem o trabalho à educação para os seus filhos e por último as características dos serviços sociais, que fazem com que muitas vezes a família opte por inserir a criança no mercado de trabalho tendo em vista os altos custos dos serviços sociais básicos ou a sua total ausência.

MADEIRA (1993) considera importante questionar a estreita conexão entre trabalho infanto-juvenil, pobreza e evasão escolar, bem como o tratamento global que, em geral, se faz da inserção no mundo do trabalho por essa parcela da população sem considerar as heterogeneidades de situações que envolvem este fenômeno no Brasil. Para essa autora, dentre os dois macrofatores citados por CERVINI e BURGER, o mais decisivo refere-se às oportunidades de trabalho oferecidas pela estrutura econômica, "o que na verdade é decisivo é a existência concreta e efetiva da possibilidade de trabalho para esta parcela da população". Afirma que a noção de pobreza não deve ser confundida com a idéia de privação absoluta na sua manifestação concreta extrema - a fome - pois uma postura reducionista não consegue captar as profundas alterações nos padrões de vida e de consumo que vêm ocorrendo na sociedade brasileira.

Observa-se a existência de trabalhos precários ligados ao tráfico de drogas. No Rio de Janeiro, 1.108 adolescentes foram presos por envolvimentos no tráfico de drogas, relatando o uso da força de trabalho juvenil nesta atividade. Uma pesquisa feita pelo Instituto de Pesquisa Econômica Aplicada (IPEA) sobre o trabalho doméstico, baseada em dados da PNAD de 96, indica a existência de 710 mil crianças e jovens entre 10 e 17 anos que trabalhavam como empregados domésticos, sendo que 90\% deste contigente é formado por meninas. Por se enquadrarem no mercado informal de trabalho, mais de $80 \%$ não têm seus direitos trabalhistas assegurados. Deste grupo, $27 \%$ não poderia, por lei, trabalhar por serem menores de 14 anos. A pesquisa indica o crescimento do trabalho doméstico de 17,23\% para 26,67\% de 1985 a 1995 .

A exploração do trabalho infanto-juvenil existe tanto em países pobres como em países ricos, mas, sem dúvidas, são as crianças empobrecidas, filhas da classe trabalhadora, as mais exploradas; que são obrigadas 
pelas circunstâncias desumanas de exploração a vender a sua força de trabalho para aumentar o rendimento familiar. Contudo, o número maior de crianças exploradas encontra-se nos países em desenvolvimento; o UNICEF (1997) estima que uma em cada quatro crianças trabalham nestes países.

\begin{tabular}{|c|c|c|c|c|c|c|c|}
\hline \multicolumn{8}{|c|}{$\begin{array}{l}\text { Percentual de crianças economicamente ativas entre } 10 \text { e } 14 \text { anos } \\
\text { do universo total de crianças em cada país. } \\
\mathbf{1 9 9 5}\end{array}$} \\
\hline \multicolumn{2}{|l|}{ África } & \multicolumn{2}{|l|}{ Ásia } & \multicolumn{2}{|c|}{ América Latina } & \multicolumn{2}{|c|}{ Europa } \\
\hline Mali & 54,5 & Butão & 55,1 & Haiti & 25,3 & Portugal & 1,7 \\
\hline Burkina Farso & 5,1 & Timor Leste & 45,3 & Guatemala & 16,2 & Albânia & 1,1 \\
\hline Burundi & 48,9 & Nepal & 45,1 & Brasil & 16,09 & Itália & 0,38 \\
\hline Uganda & 45,3 & Bangladesh & 30,1 & R. Dominicana & 16,06 & Hungria & 0,17 \\
\hline Nigéria & 45,1 & Turquia & 23 & Bolívia & 14,3 & Romênia & 0,17 \\
\hline
\end{tabular}

Fonte: OIT: International Labour Organization, Press Kits, "Chil Labour Today: Facts and Figures”, Genebra, 1996. (VEIGA, 1998).

Segundo o UNICEF (1997), da estimativa total de 190 milhões de crianças trabalhadoras com idade entre 10 e 14 anos nos países em desenvolvimento, três quartos trabalham seis dias por semana ou mais e 50\% trabalham nove horas por dia ou mais.

A exploração do trabalho infantil não se constitui um caso isolado dentro do funcionamento do sistema global, pelo contrário, encontra-se articulada à dinâmica organizacional da sociedade capitalista neste fim de século. A sua explicação e a sua intensificação têm como base as transformações que vêm acontecendo nas relações de produção e na relação hemisfério sul-hemisfério norte, não por coincidência, a presença maior da exploração do trabalho infanto-juvenil encontra-se nos países situados no hemisfério sul. Ou seja, para compreender a totalidade deste momento histórico e a sua articulação com o fenômeno do trabalho infantojuvenil, o pensamento deverá conhecer as partes que compõe o todo, a relação entre a base material e superestrutura; não numa perspectiva determinista, mas tentando descobrir os nexos, as nuanças, as várias facetas, que dão explicação a esse fenômeno neste final de século.

O sistema capitalista de produção se beneficia da exploração do trabalho de crianças e adolescentes ao empregar diretamente a sua força de trabalho e indiretamente, através da terceirização de seu trabalho na cadeia produtiva. Isto acontece porque a sua força de trabalho agrega valor na produção de mercadoria. Por outro lado, na maioria das vezes ele é única garantia de sua sobrevivência.

Fora das relações formais de trabalho, onde não se encontram protegidas pela legislação, o trabalho de crianças e adolescentes se articula com os grandes grupos internacionais através de sua utilização pelas firmas terceirizadas, como por exemplo: na indústria de calçados em Franca-São Paulo, no Rio Grande do Sul, nas indústrias automobilística e siderúrgica também se beneficiam quando consomem carvão fabricado por carvoarias que utilizam mão-de-obra infantil em condições muito perigosas;

A produção terceirizada tem no seu cerne a flexibilização dos contratos de trabalho, a desobrigação das empresas com os direitos trabalhistas, principalmente quando as empresas terceirizadas subcontratam famílias, geralmente de ex-operários demitidos, que passam a produzir em casa, com a ajuda de todos os seus membros.

No Paraná, especialmente na região dos Campos Gerais, a fumicultura é uma atividade praticada por toda a família; calcula-se que, só no município de Palmeira, mais de duas mil crianças trabalham com fumo, em que a mão de obra infantil é utilizada desde os cinco anos de idade, dela se beneficiam as grandes empresas de cigarros como a Souza Cruz e outras multinacionais.

A partir dessas constatações, pode-se deduzir que a questão da exploração do trabalho infanto-juvenil é tão abrangente e presente em diversos setores da economia, que com poucas exceções encontra-se algum produto na cadeia produtiva que não tenha a mão de crianças e adolescentes em situação irregular. A gênese desse problema está na estrutura social e nos mecanismos dos sistemas socioeconômico e político mundiais. 
Os testemunhos abaixo foram retirados do relatório final do I Tribunal Nacional contra a Exploração do Trabalho Infantil, que aconteceu em Brasília, em 11 de outubro de 1995. Eles são significativos, pois trazem o testemunho de profissionais envolvidos no combate ao trabalho infantil e fazem parte de um movimento internacional contra essa forma de exploração.

Segundo Luís Chaves (ex-subdelegado do trabalho/Montes Claros-MG), podemos encontrá-lo, por exemplo, no plantio de eucalipto, quando famílias são contratadas de maneira terceirizada para trabalhar no reflorestamento de áreas de plantação de eucaliptos, este mesmo eucalipto será utilizado pelas fábricas de papel e celulose ou para alimentar os fornos de carvoaria.

Por trás dos produtores de carvão, na outra ponta, se constata a presença de um grande grupo econômico, uma grande siderúrgica, uma grande metalúrgica. Segundo Raimundo Kappel (ex-delegado da DRT/ES), o trabalho infanto-juvenil está presente em quase todos os setores da cadeia produtiva; geralmente ele é exercido na ilegalidade, no mercado informal, posto que ele está em determinada fase da cadeia, onde o agenciador são empresas terceirizadas ou os chamados gatos e a fiscalização do Ministério Público do Trabalho - MPTb e Delegacias Regionais do Trabalho - DRT é feita com muitas dificuldades.

LEITE (1995), em pesquisa com trabalhadores de rua de 7 a 14 anos, afirma que o processo de produção que se utiliza do trabalho infantil encontra-se também articulado com o capital internacional e os fundos financeiros franqueados pelo Estado. O processo continuará tendo crianças do setor informal, com atividades aparentemente desconexas, ajudando no processo de acumulação capitalista de poderosos grupos econômicos, protegidos via patente e capital transnacional, como no caso das crianças catadoras de papel por exemplo.

Esta constatação da pesquisadora remete a alguns setores da economia que se utilizam mais intensamente do trabalho infanto-juvenil como, por exemplo, o carvão, a cassiterita e o fumo.

No ciclo do carvão, as crianças trabalham nos fornos. O carvão é ensacado e vendido para as siderúrgicas, principalmente de Minas Gerais, e para os distribuidores de São Paulo. No ciclo da cassiterita, que é retirada da terra manualmente ou por meio de máquinas, crianças atuam na fase final deste processo, trabalhando como "requeiro" (o trabalhador que busca o veio de cassiterita), quebrando pedras até 12 horas por dia, separando as que têm maior teor de cassiterita ou cavando tocas nos barrancos em busca do minério. O metal é moído e transformado em estanho por meio de processo de fundição. O setor fatura R $\$ 110$ milhões por ano.

Segundo o jornalista Mario César de Carvalho, o dinheiro do governo brasileiro financia mineradoras que usam o trabalho de crianças: "a ciranda é complexa pois envolve formas de financiamento e compras que são feitas no mercado da Bolsa de Valores." Ainda segundo esta mesma reportagem, o BNDES aplica dinheiro do PIS/PASEP (fundo de participação social criado para aumentar a renda de trabalhadores que ganham até 2 salários mínimos), que é utilizado para investimentos em grupos econômicos que se beneficiam do trabalho infantil.

Para Joaquim Carvalho, jornalista da revista Veja, o trabalho infanto-juvenil é muito importante para a produção de bens no Brasil, principalmente porque crianças e adolescentes ganham muito pouco e às vezes não ganham nada, além disso, são bastante disciplinadas, cumprem ordens melhor que os adultos e acabam de certa forma influindo no custo dos produtos. O jornalista destaca ainda alguns programas governamentais em que o Estado faz a intermediação da mão-de-obra da criança e do adolescente para algumas empresas públicas e privadas. Estes programas se articulam com empresas que contratam a mão de obra do adolescente por intermédio de convênios que assinam com o Estado, nos quais elas são dispensadas de pagar INSS, de pagar $13^{\circ}$ salário e férias.

A questão fundamental que está posta por todos estes casos é que a inserção precoce de crianças e adolescentes em trabalhos precarizados não lhes garante necessariamente uma qualificação profissional. $\mathrm{O}$ mais grave é que este tipo de trabalho é realizado com a anuência do poder público, seja através de convênios e programas intermediados pelo Estado, que favorecem a inserção de menores no mercado de trabalho sem nenhum vínculo legal, ou se utilizando de contratos precários, ou através da insuficiência do Ministério do Trabalho em fiscalizar este tipo de prática, ou através da mídia que propagandeia como legítima essa ação que precariza o trabalho e flexibiliza os direitos.

A ideologia que dá suporte a estas práticas afirma que, ao empregar a força de trabalho de crianças e adolescentes, está se prevenindo a marginalidade e além do mais, a criança trabalhando garante, pelo menos, salário mínimo para ajudar no sustento da casa. Isso é uma ilusão, pois muitas vezes o trabalho infanto-juvenil não agrega nem $10 \%$ ao orçamento familiar.

Outra informação relevante, que aponta a presença de um número significativo de jovens no mercado de trabalho informal, pode ser observada ao analisar os dados da Pesquisa Nacional de Amostra a Domicílio PNAD 97 (Curitiba e Região Metropolitana), na faixa etária de 10 a 17 anos, na categoria do emprego: 


\begin{tabular}{cccc}
\hline \multicolumn{4}{c}{ Emprego (10-17 anos) Curitiba e Região Metropolitana - 1997 } \\
\hline Faixa Etária & Emprego com Carteira & Outros & Total \\
\hline $10-14$ & 262 & 4.456 & 4.980 \\
\hline $15-17$ & 17.562 & 19.658 & 37.720 \\
\hline
\end{tabular}

Fonte: PNAD/97

Esse quadro aponta uma tendência de aumento de jovens inseridos no mercado de trabalho informal, em atividades precarizadas. Na categoria outros, estão os jovens sem carteira de trabalho assinada, com contratos de trabalho que não asseguram os seus direitos.

Deve-se considerar também nestas análises a existência de estudos que avaliam as repercussões que o trabalho infanto-juvenil precoce apresenta para a sua saúde e desenvolvimento físico e psíquico.

A princípio todo o ambiente de trabalho, em maior ou menor grau, apresenta riscos específicos para a saúde e integridade física do trabalhador. Esses riscos são mais evidentes para a criança e adolescente, devido à sua condição peculiar de desenvolvimento, pois o seu corpo encontra-se mais vulnerável por estar em fase de crescimento. Desta forma, qualquer trabalho, mesmo realizado em condições não insalubres ou perigosas, poderá ser prejudicial à sua saúde, podendo comprometer seu crescimento e desenvolvimento.

Como exemplo, o trabalho exercido em escritórios, que aparentemente não causaria nenhum mal; OLIVEIRA (1996) cita os riscos:

\begin{tabular}{cc}
\hline Principais Distúrbios & Causas \\
\hline Dores de coluna & Mobiliário inadequado
\end{tabular}

\begin{tabular}{cc}
\hline Dores musculares & Mobiliário e equipamentos inadequados \\
\hline Sonolência & Iluminação excessiva \\
\hline Cefaléia & Mobiliário e equipamentos inadequados \\
\hline Distúrbios digestivos & Permanecer muito tempo sentado \\
\hline Inflamações nos tendões & Mobiliário inadequado e esforço excessivo e repetitivo nos \\
dedos, mãos e braços (digitador)
\end{tabular}

Embora as condições históricas e sociais impostas pela sociedade capitalista às crianças e adolescentes que se inserem precocemente no trabalho levem a um amadurecimento precoce, a criança não é um "adulto em miniatura". O seu organismo encontra-se em estágio de maturação biológica, em fase de desenvolvimento físico e psicológico, que o trabalho precoce pode comprometer, deixando seqüelas irreparáveis para o resto da vida. É provável que a exposição contínua a agentes químicos, físicos e biológicos e ao trabalho excessivo comprometa futuramente o seu desenvolvimento.

Existem poucos estudos que indiquem as repercussões do trabalho sobre a sua saúde e desenvolvimento. As afirmações sobre a sua inserção nas relações de trabalho, 'pelo trabalho se previne o ócio e a marginalidade', na maioria das vezes não passam de discursos moralizantes que mistificam, por outro lado, as conseqüências danosas e formas obtusas de exploração.

Muitas tarefas desenvolvidas pela criança e pelo adolescente são nocivas para o seu desenvolvimento físico, produzindo deformações corporais e diminuição do crescimento. Pensemos nas crianças que trabalham como catadores de papel, presentes cotidianamente nas ruas de Curitiba; o peso excessivo e a postura inadequada são os que mais afetam o crescimento e provocam deformidades no esqueleto. Isso se deve ao fato de que a força, a resistência e as defesas, são tanto mais reduzidas quanto menor a idade e, nesta fase da vida, 
o organismo, ainda não maduro, está totalmente dedicado ao crescimento e sofre periódicos reajustes endócrinos e vegetativos, que são prejudicados pela carga de trabalho (OLIVEIRA, 1996).

Devemos considerar que as conseqüências para o desenvolvimento são muito nefastas, além disso, a imaturidade e a distração da criança e do adolescente os faz mais propensos aos acidentes de trabalho do que o adulto, que resultados seriam obtidos de um estudo com as crianças que trabalham nas carvoarias, cana-deaçúcar etc.?

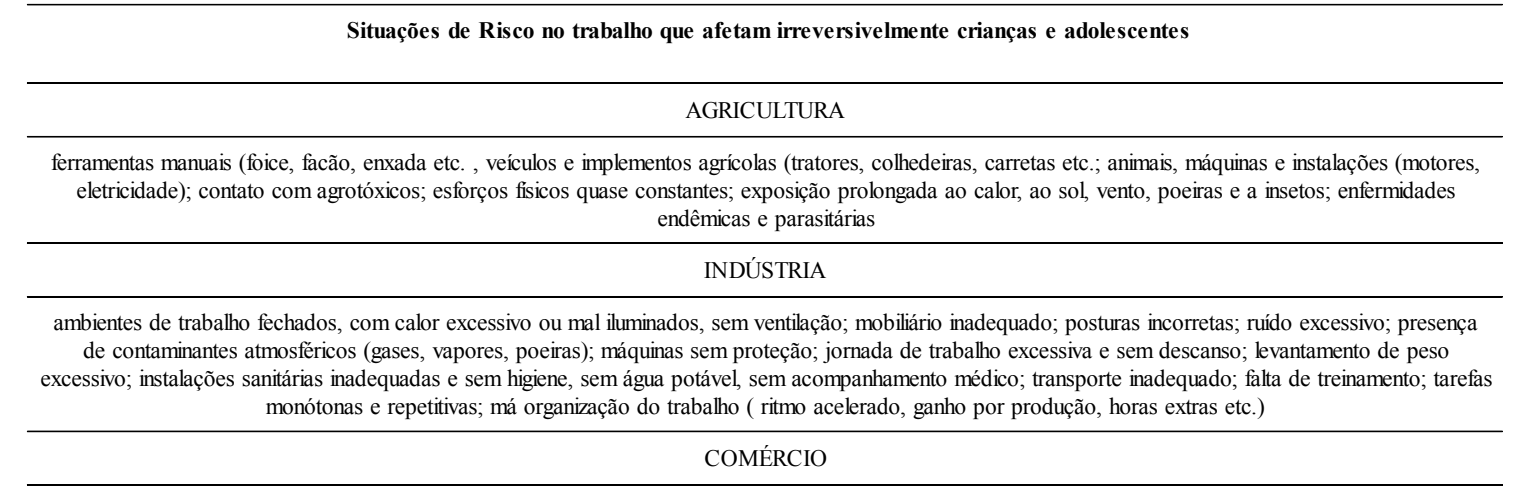

posturas incorretas; mobiliário inadequado; tarefas monótonas e repetitivas; jornada de trabalho excessiva; instalações sanitárias inadequadas e sem higiene; exposição a agentes perigosos (posto de abastecimento de veículos); trabalho noturno etc.

Além de oferecer riscos para a saúde e integridade física do trabalhador precoce, a inserção antecipada no trabalho oferece riscos para a saúde mental. De acordo com SAMPAIO (1996) a vivência da obrigatoriedade do trabalho, numa fase onde a criança e o adolescente mal ultrapassaram a fase de socialização primária, devendo estar se preparando formalmente para exercer um trabalho mais qualificado, pode trazer sérios danos para a saúde mental do adolescente.

Entendemos que os caminhos para a superação da exploração da mão-de-obra infanto-juvenil, da exclusão escolar e de condições dignas de cidadania passam por um novo modelo de justiça social e não apenas por programas paliativos e temporários. Faz-se necessário imediatamente ampliar a reforma agrária, desenvolver uma política agrícola, distribuir renda, taxar as grandes fortunas e desenvolver uma política de emprego e renda para os adultos e não para as crianças e adolescentes.

\section{REFERÊNCIAS}

CERVINI, R.; BURGER, F. O menino trabalhador no Brasil urbano dos anos 80. In: FAUSTO, A.; CERVINI, R. (Orgs.) O trabalho e a rua: crianças e adolescentes no Brasil urbano dos anos 80. São Paulo: Cortez/UNICEF/FLACSO,1991.

GRACIANI, M. S. S. Pedagogia Social de Rua: análise e sistematização de uma experiência. São Paulo: Cortez/ Instituto Paulo Freire, 1997.

KUENZER, A. Z. Ensino do $2^{\circ}$ : o trabalho como princípio educativo. 1. ed. São Paulo: Cortez, 1988.

LEITE, M. F. Criança-trabalhadora: a práxis da rua. Curitiba, 1995. Dissertação (Mestrado) - UFPR.

MARX, K. O capital. Rio de Janeiro: Civilização Brasileira, 1980.

MADEIRA, F. R. Quem mandou nascer mulher? Estudos sobre crianças e adolescentes pobres no Brasil. Rio de Janeiro: Record/Rosa dos Tempos, 1997.

MIRANDA, S. G. A exploração do trabalho infantil: mitos que a sustentam, caminhos para a superação. 1998. Mimeog.

OLIVEIRA, J. F. de. O trabalho da criança e do adolescente em condições de risco. mimeog., 1996.

OLIVEIRA, M. de L. B. de. Infância e Historicidade. São Paulo, 1989. Tese (Doutorado em Educação) - PUC.

RIZZINI, I.; HOLANDA, F. B. de. A criança e o adolescente no mundo do trabalho. Rio de Janeiro: USU/Amais, 1996.

PEREIRA, I. (Org.). Trabalho do adolescente: mitos e dilemas. São Paulo: IEE/PUC,1994.

TONIN, M. M. Análise conjuntural da realidade mundial e brasileira. In: SEMINÁRIO CRIANÇA E ADOLESCENTE EM SITUAÇÃO DE RISCO: UMA COMPREENSÃO NECESSÁRIA (1996: Curitiba). Anais...Curitiba: IMAP, 1996. 
VEIGA, J. P. C. A questão do trabalho infantil. In: DEDECCA, C. S. (Org.). Mercado de trabalho. São Paulo: ABET, 1998. v. 7.

\section{ARTIGOS DE JORNAIS E REVISTAS}

VEJA, 22 set. 1999, p. 30.

ISTO É, Infância roubada, 07 maio 1997.

MARIE CLAIRE, Meninos sapateiros: um pé lá outro cá. 1998.

MÃO de obra infantil é comum no plantio de fumo. GAZETA DO POVO, Curitiba, 02 fev. 1998.

TRABALHO domésticos. Folha de São Paulo, 12 dez. 1998.

TRABALHO infantil: infância roubada. Folha de São Paulo, 1 maio 1997. 